\title{
Treatment of bipolar mania with obsessive symptoms with clozapine: a case report
}

\author{
Shubhangi Parkar, Chetali Dhuri, Rueeta Athalye
}

\section{Summary}

Obsessive compulsive disorder (OCD) and bipolar disorder can be comorbid, although the exact pathogenesis of obsessive compulsive symptoms (OCS) in bipolar disorder is not clear. Bipolar disorder and OCD can co-occur either due to independent aetiologies or due to the hyposerotonergic state caused by treatment with atypical antipsychotics leading to emergence of OCS. Clozapine, an atypical antipsychotic has been repeatedly implicated in de novo emergence or exacerbation of OCS. In this case report, we describe an elderly man with bipolar disorder currently manic and OCS who was successfully treated with clozapine

SL J Psychiatry 2013; 4 (2):42-43

\section{Introduction}

Obsessive compulsive disorder (OCD) has a complex relationship with bipolar disorder. The Epidemiologic Catchment Area study (1984) reported that bipolar euthymic patients have 18 times higher risk of developing OCD in comparison with the general population (1). A study by Chen and Dilsaver reported that lifetime rates of OCD among probands with bipolar disorder were $21 \%$ (2). Raja et al analyzing data from a large nation-wide sample found that for those with either Bipolar I or II (most had Bipolar II), 21\% had co-morbid OCD (3). Obsessive compulsive symptoms (OCS) can accompany either depressed mood or elevated mood. Findings suggest that in most cases OCS subside during manic episodes and reappear after remission of mania or at the beginning of depressive episodes $(4,5)$. However, there are isolated case reports of manic and OCS symptoms occurring together (6).

Patients with bipolar disorder and OCD are amongst the most difficult to treat as no mood stabilizer has been shown to specifically reduce OCS. Serotonergic drugs effective in treating OCD have high risk of exacerbating mania. Many atypical antipsychotics such as olan $\neg$ zapine, risperidone and quetiapine commonly used in treating mania are reported to precipitate or worsen OCS (7). Clozapine is the atypical antipsychotic implicated the most for precipitating or exacerbating pre-existing OCS $(8,9)$.

In this case report, we describe an elderly man with bipolar disorder currently manic and OCS who was successfully treated with clozapine.

\section{Case report}

A 63-year-old man presented with elevated mood, talkativeness, hyperactivity, hyper-religiosity, decreased need for sleep and increased energy. He believed that he had relations with religious and political figures and heard their voice commanding him to help others. During this period there were prominent obsessions of contamination and washing rituals. These symptoms were present over the last 2 months.
The patient has a history of bipolar disorder since adolescence (for approximately 45 years). During the previous episodes he frequently cleaned his house and courtyard and had outbursts of anger if he found garbage anywhere. Clinically significant OCS emerged only during the current episode of mania and these symptoms were disabling. He also had extrapyramidal symptoms-slurring of speech, rigidity and tremulousness. There were no features suggestive of an organic aetiology.

He had been hospitalized several times during relapses of acute mania and depression and had been treated with electroconvulsive therapy. He was poorly compliant with medications. The best response was seen with a combination of lithium 900-1500mg and haloperidol. Because he was diagnosed with chronic renal disease lithium was discontinued and oral divalproex sodium was commenced. At the time of presentation he was on divalproex sodium $1000-1250 \mathrm{mg}$ and haloperidol $10-15 \mathrm{mg}$. There were no features suggestive of other medical or surgical illnesses. Routine haematological and biochemical investigations and magnetic resonance imaging of the brain were normal.

Because of the severity of symptoms, extrapyramidal side effects and the poor response to the current treatment, patient was started on quetiapine. The dose was gradually increased to $200 \mathrm{mg}$ but there was minimal improvement. Patient continued to be agitated and elated mood and grandiosity persisted. He slept only about two hours at night and was seen cleaning the floor and the windows of the entire 60 bed ward. Because of concerns that such severe exertion would be detrimental to physical health of this elderly patient, clozapine was commenced. Treatment was started at 50 $\mathrm{mg} /$ day and titrated to $300 \mathrm{mg} /$ day. There was significant improvement of mania. Along with improvement of manic symptoms, disabling OCS also improved significantly.

\section{Discussion}

Clozapine has potent $5 \mathrm{HT} 2 \mathrm{~A}$ and relatively weak Dopamine D2 receptor antagonism. It has a unique mechanism of action, with affinity to several neuroreceptors and maximal 5-HT2A:D2 affinity ratio compared to other 
atypical antipsychotics. Recent reports on the emergence of OCS in patients treated with clozapine support the hyposerotonergic hypothesis of OCD (10). The association of OCS and clozapine treatment can be explained by the strong antagonistic activity at postsynaptic serotonergic receptors compared to other atypical antipsychotics.

Our patient achieved remission of both manic and OCS with clozapine treatment. The remission of both types of symptoms can be attributed to numerous factors. Clozapine as a mood stabilizer has better anti manic than anti depressive properties and is effective in the treatment of manicexcited phases of schizoaffective and bipolar disorders in patients who have shown poor response to conventional pharmacotherapy $(11,12)$. A study assessing the real world effectiveness of clozapine in patients with bipolar disorder has reported a significant reduction in the number of beddays, psychiatric admissions, psychotropic co-medications, and hospital contact for self-harm/overdose making it a preferred medication in difficult to manage bipolar patients and not only for treatment refractory patients (13).

The OCS in our patient may be a feature of the bipolar illness, and the remission of the bipolar symptoms could have led to the remission of the OCS symptoms as well. This is supported by the concept originally proposed by Kraeplin who considered anxiety as symptom of bipolar disorder (14). Current research strongly supports the concept of anxiety-bipolar spectrum as evidenced by high rates of co-morbid anxiety disorders such as panic disorder, social phobia, and OCD in bipolar disorder compared to population controls (15). Similar case reports where OCS has subsided with the use of mood stabilizers like lithium and sodium valproate in manic patients further support this hypothesis (6).

Our case report highlights the fact that OCS may be an epiphenomena of bipolar disorder and thus need not be always be diagnosed as a separate condition and treated separately. Though atypical antipsychotics and especially clozapine has been associated with emergence of OCS, the significance of this finding is still unclear. It is not clear whether OCS symptoms emerged due to treatment with clozapine or other antipsychotics or as part of the natural history of OCD (16). In fact case series, open label trials and placebo-controlled trials suggest that augmentation of antidepressants with antipsychotics is effective in the treatment of refractory OCD (17).

The co-occurrence of bipolar disorder and OCS needs to be explored further. There isn't sufficient evidence yet to clarify if it is an epiphenomenon or part of the anxiety-bipolar spectrum. Although efficacy of clozapine in the treatment of mania is established, further research is necessary to understand its role in treating OCS in bipolar mania.

\section{Declaration of interest}

None declared

Shubhangi Parkar, Chetali Dhuri, Rueeta Athalye,

Department of Psychiatry, Seth G. S. Medical College and

KEM Hospital, Parel, Mumbai, India

Corresponding author: Shubhangi Parkar

E mail:pshubhangi@gmail.com

\section{References}

1. Boyd JH, Burke JD Jr, Gruenberg E et al. Exclusion criteria for DSM III.A study of co-occurrence of hierarchy- free of syndromes. Arch Gen Psychiatry 1984;41:983-9.

2. Chen YW, Dilsaver SC. Comorbidity for obsessivecompulsive disorder in bipolar and unipolar disorders. Psychiatry Res. 1995;59(1-2):57-64.

3. Raja M. Comorbidity and management of obsessive-compulsive disorder and bipolar disorder. Directions in Psychiatry 2005;25(3):183-196.

4. Raja M,Azzoni A. Case Report Clinical management of obsessive-compulsive-bipolar comorbidity: a case series. Bipolar Disord 2004; 6:264.

5. Keck PE Jr, Lipinski JF Jr, White K. An inverse relationship between mania and obsessive compulsive disorder: a case report. J Clin Psychopharmacol 1986;6:123-124.

6. Shabani A, Eftekhar M, Abedian S. Changes in Obsessive Compulsive Symptoms during Manic Episodes: A case series. Iran J Psychiatry 2007;2:8285.

7. Lykouras L, Alevizos B, Michalopoulou P, Rabavilas A. Obsessive-compulsive symptoms induced by atypical antipsychotics. A review of the reported cases. Prog. Neuro-psychopharmacol. Biol. Psychiatry 2003; 27:333 - 346

8. Ertugrul A, Yagcioglu E, Eni N, Yazici K. Obsessive-compulsive symptoms in clozapinetreated schizophrenia patients. Psychiat Clin Neuros 2005;59:219-222.

9. Patil VJ. Development of transient obsessivecompulsive symptoms during treatment with clozapine. Am J Psychiatry 1992;149:272.

10. Toren P, Samuel E, Weizman R, Golomb A, Eldar $\mathrm{S}$, Laor N. Case study: emergence of transient compulsive symptoms during treatment with clothiapine. J Am Acad Child Adolesc Psychiatry 1995 Nov;34(11):1469-72.

11. Zarate CA. Antipsychotic drug side effect issues in bipolar manic patients. J Clin Psychiatry 2000; 61:52-61.

12. Calabrese JR, Kimmel SE, Woyshville MJ, Rapport DJ, Faust CJ, Thompson PA, Meltzer HY. Clozapine for treatment-refractory mania. Am J Psychiatry 1996; 153:759-764.

13. Nielsen J, Kane JM, Correll CU. Real-world effectiveness of clozapine in patients with bipolar disorder: results from a 2-year mirror-image study. Bipolar Disord. 2012 Dec;14(8):863-9.

14. Kraepelin E. Manic-depressive insanity and paranoia. Edinburgh: Livingstone 1921.

15. Angst J. The emerging epidemiology of hypomania and bipolar II disorder. J Affect Disord. 1998;50(23):143-151.

16. Ghaemi S, Zarate C, Popli A, Pillay S, Cole J. Is there a relationship between clozapine and obsessivecompulsive disorder? A retrospective chart review. Compr Psychiatr 1995;36:267-270.

17. Sareen J, Kirshner A, Lander M, Kjernisted KD, Eleff MK, Reiss JP. Do antipsychotics ameliorate or exacerbate Obsessive Compulsive Disorder symptoms? A systematic review. J Affect Disord. 2004 Oct 15;82(2):167-74. 